\title{
Role of Malaysian Non-Governmental Organizations in Malaysia-China Educational Exchange under Malaysian Ethnic Politics
}

\author{
Xia Nan ${ }^{1} \&$ Yang Yanan ${ }^{2}$ \\ ${ }^{1}$ School of International Education, Chengde Medical University, Chengde, China \\ ${ }^{2}$ Social Science Department, Chengde Medical University, Chengde, China \\ Corresponding author: Xia Nan, School of International Education, Chengde Medical University, 067000, \\ Chengde, Hebei, China. Tel: 86-136-7324-9354.
}

Received: September 3, 2018

doi:10.20849/ajsss.v3i3.477
Accepted: September 21, $2018 \quad$ Online Published: September 26, 2018

URL: https://doi.org/10.20849/ajsss.v3i3.477

\begin{abstract}
Educational exchange between Malaysia and China has an important interaction with the Chinese education in Malaysia and the political relations between Malaysia and China. Chinese education in Malaysia is twisted with Malaysian ethnic politics. Malaysian Chinese students were lack of opportunities at the public institutions of higher learning due to the preferential and affirmative action policies implemented by Malaysian government under the egis of New Economic Policy (NEP).Thus, Malaysia NGOs (Non-Governmental Organizations) carried out educational exchange with China to open up a more spacious study channels for students. The objective of this article is to investigate the role of Malaysian NGOs towards educational exchange between Malaysia and China under Malaysian ethnic politics. Primary data were collected through interviews and the informants were selected based on purposive sampling and snowball sampling. Totally, fourteen informants were selected and interviewed based on evidence of data saturation. Secondary data were collected from journal articles, newspapers, website pages and online resources. Meanwhile, structuration theory was used to guide the researcher to get the suitable answer. Findings of this study indicate that, there are three main important NGOs that play a significant role in promoting educational exchange between Malaysia and China, which are Dong Jiao Zong (the collective name of Dong Zong and Jiao Zong), the Association of Graduates from Universities and Colleges in China, Malaysia (AGUCCM) and Malaysia-China Friendship Association (MCFA). As the purposive actors, they conduct their actions based on different levels, which are to develop Chinese education in Malaysia, to continue and inherit Chinese culture. Their unconsciousness reason is based on Malaysian Chinese's deep feeling to China. Moreover, the educational exchange in the aspect of Chinese education is conducted under the structure of Malaysian ethnic politics, which led to a dichotomy. Nowadays, with the rise of China and the promotion of "the Belt and Road", educational exchange between Malaysia and China will become better and better.
\end{abstract}

Keywords: role, Malaysian NGOs, Malaysia-China, educational exchange, ethnic politics

\section{Introduction}

The friendly relations between Malaysia and China have a long history. Malaysia and China established formally diplomatic relations since May 31, 1974, which made Malaysia was the first major Southeast Asian country to exchange diplomatic recognition with China. The bilateral relations between Malaysia and China are mainly based on the economic and trade fields, followed by tourism, and then is the field of education. As one of the most important aspects of Malaysia-China relations, the development in educational area is lagging behind due to many reasons. It was not until the year of 1997 when the government between Malaysia and China signed Memorandum of Understanding (MOU) on Education Cooperation that opened a prelude to educational cooperation between the two countries.

Educational exchange between Malaysia and China is significant to Malaysia and China relationship, which has an important interaction with the local Chinese education and the political relations between Malaysia and China. Chinese education in Malaysia is twisted with Malaysian ethnic politics. Malaysian Chinese students were lack of opportunities at the public institutions of higher learning due to the preferential and affirmative action policies 
implemented by Malaysian government for the majority community under the egis of NEP (Raman \& Sua, 2010). Under this circumstance, Malaysian NGOs carried out educational exchange with China to open up a more spacious study channels for students of the independent Chinese secondary schools in Malaysia. Thus, the objective of this article is to investigate the role of Malaysian NGOs towards educational exchange between Malaysia and China under Malaysian ethnic politics.

\section{Material and Methods}

Data of this article is based on two sources, primary data were collected through interviews and the informants were selected based on purposive sampling and snowball sampling, meanwhile, secondary data were collected from journal articles, newspapers, website pages and online resources. The primary data of this article were collected through in-depth interviews. Totally, fourteen informants were selected and interviewed based on evidence of data saturation. In order to make sure that all data are collected with appropriate anonymity and confidentiality, names of the informants were coded with letters and numbers, such as A1, B2, and C1. Based on this research, these fourteen elites were divided into three politicians coded as A, seven social activists coded as B and four scholars coded as C. These politicians include former Malaysian Ambassador to China, former Deputy Minister of Education, and Deputy Minister of Higher Education and Deputy Ministry of Home Affairs of Malaysia. The social activists include political commentators, cultural worker and so on. Scholars include senior lectures and professors in universities and research institute in Malaysia. These informants have rich experience and knowledge in ethnic politics in Malaysia and educational exchange which could provide sufficient data for this study. Meanwhile, content analysis was used to analyze the collected primary data and also the secondary data which were collected from journal articles, newspapers, website pages and online resources.

Meanwhile, based on the research objective, structuration theory was used to guide the researcher to get the suitable answers. Structuration theory which was proposed and developed by British sociologist Anthony Giddens, with its focus on social practices, is a theory of the relationship between agency and structure (Ritzer, 2010). In Giddens's theory of Structuration, he tries to balance the role that actors play with their limited choice of position in history and in the social fabric they find themselves, people are the element that recreate the social structure and produces social change. In Giddens's view, agency posits the person as reflexive, able to monitor his/her experience and give reasons for his/her actions, which means agency can justify their actions. Agency is composed of three levels, which are discursive consciousness, practical consciousness and unconsciousness. Discursive consciousness refers to the capacity of agency to "give reasons" and "rationalize" their conduct and motivations, whereas practical consciousness is the "stocks of unarticulated knowledge and belief" that people use to orient themselves to situations and interpret the acts of others (Turner, 1986). The unconsciousness is that which cannot easily be put into words and resides beneath our conscious existence, Giddens states that people have unconscious motivations for trust and security, but the unconscious are rarely motivates their behavior directly. Structure is defined as "the structuring properties [rules and resources] ... the properties which make it possible for discernibly similar social practices to exist across varying spans of time and space and which lend them systemic form" (Giddens, 1984). For Giddens, social structure is both enabling and constraining for human action. In other words, structure often allow agents who have the ability to make a difference in the social world to do things they would not otherwise be able to do, nevertheless, constraint for Giddens means placing limits on the number of paths which people can pursue in a given social situation.

According to structuration theory, structure is those factors of influence (such as social class, religion, gender, ethnicity, customs, etc.) that determine or limit an agent and his or her decisions, hence the ethnic politics is regarded as the structure in Malaysia, and this structure determines or limits the Malaysian NGOs' decision. Malaysian NGOs are as the agentive entities have their independent capability to make decisions and take actions. But the structure of ethnic politics constrains the behavior of Malaysian NGOs. As the major NGOs are purposive actors, they make their decisions, so this structuration helps the researcher to analyze why and how they make their decision under the structure of Malaysian ethnic politics. This theory is also useful to determine the roles of Malaysian NGOs in the process of promoting educational exchange in the ethnic politics structure.

In addition, as the purposive agencies, Malaysian NGOs conduct their actions to promote educational exchange between Malaysia and China. They rational their action based on their knowledge and experience. In other words, Malaysian NGOs promoted educational exchange based on three different levels, i.e. discursive consciousness, practical consciousness and unconsciousness. However, Malaysian NGOs had to conduct their actions under certain structure, i.e. Malaysian ethnic politics. On one hand, Malaysian ethnic politics constrains and restricts Malaysian NGOs' actions, in other words, Malaysian NGOs had to follow the rules through their process of promoting educational exchange. On the other hands, resources which are under the Malaysian ethnic politics 
facilitate Malaysian NGOs' actions. Malaysian NGOs have their own resources (material equipment and organizational capacities), which helped them to mobilize power to promote educational exchange. In other words, Malaysian NGOs have the ability to achieve their achievement under Malaysian ethnic politics. In sum, the structuration theory can guide this research to solve the research question.

\section{Results and Discussion}

According to structuration theory, NGOs, as the purposive actors, they rationalized their social conduct. Therefore, the following three agents conduct their action to promote educational exchange between Malaysia and China with different kinds of motivations including the discursive consciousness, practical consciousness and unconscious motives. Meantime, they are under certain structure that may enable and constrain their actions. Hence, in this part, the author scrutinized and gave the short introduction of these NGOs first, and then discussed their motivations in promoting educational exchange between Malaysia and China, finally examined the roles of these NGOs under Malaysian ethnic politics.

\subsection{The Role of Dong Jiao Zong}

Dong Jiao Zong is the collective name of Dong Zong and Jiao Zong, which is the main organization to develop and promote Chinese education in Malaysia. Besides, it promotes educational exchange between Malaysia and China in its own way.

\subsubsection{Brief Introduction of Dong Jiao Zong}

Dong Zong also known as the United Chinese School Committees' Association of Malaysia (UCSCAM) was established on 22 August 1954. Dong Zong which has a broad social foundation is one of the important Chinese communities, whose mission is to defend and develop Chinese education. Dong Zong has been playing not only as the nanny of Chinese schools in Malaysia but also as the "non-governmental Ministry of Education" since the mid-1970s (Lew, 2006, p. 146).

According to Dong Zong, there are nine objectives of its establishment which are as following:

1. Unite members of the Association to safeguard and develop Chinese Education in Malaysia.

2. Study and promote matters on the building and reform of Chinese schools in Malaysia, including matters regarding curricula, examinations, teachers, education funds and others.

3. Enhance and strengthen the connection among members of Chinese School Boards in the country.

4. Rally the power of the Chinese communities in Malaysia to strategise together on improving and promoting matters relating to Chinese Education.

5. Represent the Chinese School Management Boards of all Chinese Schools in Malaysia to discuss and negotiate with the government on all matters relating to Chinese Schools.

6. Plan and strategise on the cooperation between Chinese School Boards and Chinese School teachers in Malaysia.

7. Promote the goodwill and unity among the various races.

8. Purchase, lease or exchange, hire-purchase or acquire in any other form movable or immovable properties deemed by the Association as beneficial to its objectives.

9. Manage all or any part of the Association's properties, whether through sale, management, lease, charging of fees, construction or any other means of handling.

Jiao Zong also known as the United Chinese School Teachers' Association of Malaysia (UCSTAM) was established on 25 December 1951. It is the first nongovernmental organization in Malaysia to defend the mother tongue education. As discussed before, the release of the Barnes Report contributed to its establishment. Dong Zong which is different from the other common organizations that seek personal welfare was established for the equality of Chinese education and citizenship of Chinese in Malaysia. According to Jiao Zong, there are three objectives of its establishment. The first is to connect the teachers of Chinese schools in Malaysia, seek their welfare and develop the Chinese culture. The second is to study and promote education. The third is to fight for the equality of Chinese education and citizenship of Chinese in Malaysia.

After their establishment, Dong Zong and Jiao Zong have worked closely to fight for the Chinese education in Malaysia and the ethnic rights of the Chinese community. It can be said that the intervention of the British colonial government's various education policies or decrees directly contributed to the combination of Dong Zong and Jiao Zong (Lim, 1999), which became close allies, and together were then named "Dong Jiao Zong". 
After half a century of struggles, Dong Jiao Zong has become the spokesperson for Chinese Education in Malaysia. In addition, they will remain their close relationship to promote Chinese education in Malaysia.

\subsubsection{Motivates of Dong Jiao Zong in Promoting Educational Exchange}

According to the Structuration theory, the agent has three levels of motivations including discursive consciousness, practical consciousness and unconsciousness motivations to conduct his action, similarly, as the collective agent, Dong Jiao Zong promoted educational exchange between Malaysia and China based on three kinds of motivations according to the analysis of the data. Based on Structuration theory, it could be easier to analyze the reason that Dong Jiao Zong promoted education exchange.

The first reason is based on their discursive consciousness. This, in a nutshell, is to develop Chinese education in Malaysia. This has consideration of two following respects mainly. The first was to provide access to higher education and solve the problem of further study for students especially those in the independent Chinese secondary schools. The second was to train the Chinese teachers. Informant B1 pointed out that "the issue of higher education was a great pressure and problem for Malaysian Chinese in 1980s and 1990s, which caused the Malaysian Chinese dissatisfaction with the government." Informant B6 and $\mathrm{C} 1$ agreed with B1 and $\mathrm{C} 1$ added that "many Malaysian students especially the independent Chinese secondary school students went to study in China, because they cannot enter the public universities". Hence, under this circumstance Dong Jiao Zong went to China to solve the problem of further study for the independent Chinese secondary school students. Informant B5 said that:

In addition to solve the problem of further study for the independent Chinese secondary school students, the most important thing was to establish contact with China, because we had never been there. So the first was to establish contact and let China know about Malaysia, meantime, we also understood the situation in China.

Besides, informant B4 pointed out that "another reason was that due to the lack of the Chinese education in Malaysia, we wished that Malaysian student who went to study in China could come back and take this responsibility, and finally to develop the Chinese education in Malaysia".

The second reason is due to their practical consciousness. They took it for granted that educational exchange could play an important role in the continuity and inheritance of Chinese culture. Informant A3 said that "Chinese education in Malaysia is not only a language but also a carrier and channel of Chinese culture. From the beginning of primary school we began to be influenced by Chinese culture and Chinese values. So Chinese education has its mission to carry on and inherit Chinese culture". Informant A2 added that "it was because that we Chinese were educated by Chinese education, and then these Chinese naturally thought of going to China to study". Informant B4, C2 and C3 agreed with what A2 and A3 said, in addition, informant B2 said that it was a natural process to continue and inherit Chinese culture and promote education exchange. Hence, it was due to the practical consciousness to inherit Chinese culture and to promote educational exchange.

The third reason is on account of their unconscious motives. In other words, Malaysian Chinese especially those, who were the early immigrants to Malaysia and educated by Chinese education, have deep feelings for China, which made them trace back to China and promote education exchanges. Informant B7 said that "we have same culture and same race as China. We go to study in Chinese schools in Malaysia mainly because we love Chinese culture, so we had a desire to go to China, those who were educated in English would not go there". Informant B3 said emotionally that:

My ancestral home is Hainan Province, China. I grew up in Hainan and I was educated for many years in China. The first song I can sing was Dong Fang Hong (The East is Red). I was a member of the Young Pioneers of China. I came to Malaysia after the liberation of China and some of my relatives like my cousins are in China now. Therefore, I had strong feeling with China. When I went back to China, I sought root and I was very excited due to my childhood memories. Hence, in that background we went to China and promoted educational exchanges.

Besides that, informant B5 and C4 showed their mentality to China due to the historical reasons, informant B5 pointed out that:

It's a little more complicated for the Malaysian Chinese community. In terms of history and emotion, we are supportive of China. Actually, there is no way to break the kind of nostalgia. It is impossible to break it all at once. However, there are some gradual changes and the new generation is different. Like our age, we followed Socialism when we were in universities and we were greatly influenced by China in 1970s and 1980s. Therefore, because Malaysian Chinese had such lineages or cultures in history, coupled with the oppression here (in Malaysia), most of the Chinese tended to be emotional towards China. 
In addition, informant $\mathrm{C} 4$ expressed the eagerness of Malaysian Chinese when they were allowed to go back to China. He indicated that:

Emotionally, the mentality of the Chinese in Malaysia had been consistent since the early days of our independence. We were not allowed to go to China though Malaysia and China established diplomatic relations in 1974. We waited for a long time and our mind were eager. When we were allowed to go to China, we immediately went there and you saw that people to people exchanges began to become more and more. It was clear that the mentality of the Malaysian Chinese kept deep feelings to China when they were changed from the overseas Chinese to Malaysian Chinese. Hence, the feelings were certainly stronger when Malaysian Chinese looked at China at that time, but it began to slowly wither after 1993.

In sum, as discussed above, there were three main reasons that made Dong Jiao Zong promote educational exchange between Malaysia and China. With deep feelings for China, they thought that educational exchange could play an important in the continuity and inheritance of Chinese culture and develop Chinese education in Malaysia, thus they used their own ways to promote educational exchange between Malaysia and China.

\subsubsection{Role of Dong Jiao Zong in Promoting Educational Exchange}

From the mid-1950s to the late 1980s, the Chinese youth were prevented by the Malaysian government from going to mainland China for further study because of concerns about the influence of the communism (Xu, 2004). Meantime, the Chinese were allowed to visit the mainland China before 1989. Hence, the Malaysian Chinese students chose to study in Taiwan, according to informal statistics, there are about 60,000 Malaysian students who are graduated from universities from Taiwan.

It was not until 1990s that Dong Jiao Zong contacted with China. One was due to Malaysian release to allow going to China, another reason was because of Malaysian Chinese's strong feelings about China. Just as informant B3 said:

That kind of feeling was very strong, we went back to root, meantime, at that time, Dong Jiao Zong was at very low points, one was the failure of the Medeka University, another was due to the Operasi Lalang, some of the leaders of Dong Jiao Zong like Sim Mow Yu, Lim Fong Seng and so on were arrested in jail. After coming out from jail, Lim Fong Seng advocated to the establishment of New Era University, at that moment we went to China.

Actually, at that time, Dong Zong was not familiar with China, so before they went to China, there was one person who was the pioneer to China, just as informant B5 said that:

Because Dong Zong was not familiar with China at that time, so they conveyed their will by one person named Ai Wei, who was a female writer in Malaysia and in contact with China. Then Ai Wei came back from China with a message that Liao Shengdai would invite us to visit China. However, Dong Zong did not want to, and then Jiao Zong sent three people including me as secretariat chief executive officer to China, where we were received hospitably by Liao Shengdai who worked in the Ministry of Culture and Education and several other doctors.

Hence, on May 8, 1993, shouldering an important historical mission of pioneers, Foo Wan Thot who was the Chairman of Dong Zong led the educational exchange delegation of Dong Jiao Zong to China for a 14-days visit. There were ten persons in this delegation, which including Foo Wan Thot, Shen Muyu who was the Chairman of Jizo Zong, and Lu Tingyu who was the Vice Chairman of Jizo Zong, the Secretariat Chief Executive Officer of Dong Zong Bock Tai Hee, and Yow Lee Fung who was the Secretariat Chief Executive Officer of Jiao Zong and so on. This visit was the first time in the history for the Malaysian private education groups carrying out educational exchange with China, which was called "Ice Break".

This visit tied up educational and cultural exchanges people-to-people once again, which had been interrupted for nearly half a century. Dong Jizo Zong seized the opportunity of people-to-people exchanges between Malaysia and China in the first time to visit China in order to open up a more spacious study channels for students of Chinese independent high school in Malaysia, which made the educational exchange delegation of Dong Jiao Zong to be the first private education group in Malaysia to visit China. Besides, this visit built a cultural bridge between Malaysia and China. Moreover, it made China has a more comprehensive understanding on the ups and downs and the status quo of Chinese education in Malaysia in the past two centuries, which had an extraordinary significance on educational exchange between Malaysia and China in the future.

The delegation visited more than 13 universities in China including Tsinghua University, Peking University, Beijing Normal University, Fudan University, Xiamen University, and Jinan University and so on. Meantime, 
they also met with the China Overseas Exchange Association and Confucius Institute Headquarters (Hanban) and Guangdong Overseas Exchange Association the Higher Education Bureau etc.

Since then, the Malaysian Chinese students form Chinese independent secondary schools, national-type secondary schools and national secondary schools that have gone to China for further study have been increasing; the road to further study becomes broader. What is more, the exchange on Chinese education in Malaysia and Chinese culture between Malaysia and China became more frequent, especially in terms of improving teaching performance and curriculum design.

\subsection{The Role of the Association of Graduates From Universities and Colleges in China, Malaysia (AGUCCM)}

The Association of Graduates from Universities and Colleges in China, Malaysia (AGUCCM) was approved by the Registry of Societies of Malaysia (Jabatan Pendaftaran Pertubuhan) in May 2005 and established in October 10 that year. Members of AGUCCM are from the graduates of universities from mainland China as well as Hong Kong, Macao and Taiwan. Just as informant B5 said that:

At the very beginning, members of AGUCCM are not so many, and most of the members are individual members, it was not like the Federation of Alumni Associations of Taiwan Universities, Malaysia (FAATUM) who was composed of many alumni and each alumnus has a lot of members. AGUCCM may also try to do some alumni like the Alumni Association of Jinan Universities, however, because there were not so many graduates, it will not so successful.

The main reason for the establishment of AGUCCM is that with the changes of the international situation in recent years, China's national strength has increased and the use value of the Chinese language is more extensive, moreover, it becomes a trend to go further studies in China. Students in Malaysia also began to study in China, however, due to the lack of complete study materials and information, it often caused a waste of energy and many trouble in the process of application, and ultimately failed. AGUCCM seized the chance to cooperate with the relative unites of China, informant B5 pointed out that:

So at the beginning, I was very clear that at that time during 2005 and 2006, China began to hold the Summer Campus and Winter Campus and so on for Malaysian students and there were more than one hundred places. Actually, these campus were given to Dong Zong, however, due to the changes in personnel, Bock Tai Hee left Dong Zong and Yap Sin Tian became the president of Dong Zong, so Dong Zong did not take these Summer Campus and Winter Campus, then AGUCCM seized this chance and started with this as a starting point. Since then there was a channel to communicate with China. Later, they communicated with Fujian Province, China. Ting Chee Seng has good personal relationship with officials of Overseas Chinese Affairs Office of Fujian Provincial People's Government.

The AGUCCM actively promotes the Chinese education and Chinese culture; in addition it contributes to the educational exchange between Malaysia and China. There are two main contributions of AGUCCM. Firstly, it strives for more benefits for Malaysian students in China and those who are going to study in China. The AGUCCM provides the latest counseling information to students who are interested in studying in China; meantime, it also helps students who are studying in China to solve their problems. In addition, it strives for more benefits including scholarships, preferential tuition fee and accommodation fee from Chinese related units and the Malaysian authorities through the organization's strength.

As early as 2006, in view of the constant demands of the Malaysian Chinese community for tuition fees, Zhang Tiegen who was the consul general for the People's Republic of China in Kuching said that he would like to reflect to the Chinese government to try to reduce tuition fees (Shi \& Pan, 2011). Actually, since its establishment, the AGUCCM has won a lot of benefits for Malaysian students. For example, in 2005 AGUCCM had won 30 scholarships, preferential tuition fee and accommodation fee from Huaqiao University, besides, it had won more places for Malaysian students from other universities including Jinan University in China.

Secondly, it carries out foreign exchange. AGUCCM is in close contact with Embassy of the People's Republic of China in Malaysia. Since its establishment, AGUCCM has organized the youth to China for the Summer Campus and Winter Camps to make them experience Chinese culture more deeply. Such as the Winter Camps for Malaysian Chinese youth 2006 was held in Chinese Language and Culture College of Huaqiao University and so on. These Summer Campus and Winter Camps are conducive to the mutual understanding and enhancement of friendship between the young people of Malaysia and China; besides, it can also encourage more Malaysian students to study in China.

The AGUCCM hopes to create more opportunities for teachers engaged in Chinese education to study new Chinese teaching skills in China. Commissioned by Overseas Chinese Affairs Office of the State Council and 
Provincial Overseas Chinese Affairs Offices of China, AGUCCM plans to organize various types of short-term training courses including Chinese teacher training class, Chinese multimedia teaching of Mandarin pronunciation teaching classes and so on to go to related universities in China to study. Besides, it also introduces excellent teachers to enhance the local teaching level. In recently years, GUCCM directly invited China's best teachers to Malaysia to face-to-face teaching the Chinese, multimedia teaching and subject teaching teacher training courses in order to enhance the image of Chinese education in Malaysia. Moreover, the AGUCCM recommend secondary school graduates to College of Chinese Language and Culture, Jinan University for the Overseas Chinese Education undergraduate in order to reserve Chinese education teachers for Malaysia. These students are entitled to full scholarships and free accommodations. At the same time, AGUCCM maintains close cooperative partnership with Huaqiao University, Zhejiang University, Nanjing Normal University, and Tianjin University and so on.

In addition, informant B7 who was the former president and one of the founders of AGUCCM established the CC CAMPUS NETWORK SDN BHD in 2016 to special counsel and encourage students to study in China. He said that "I have been the president of AGUCCM for 11 years. I think I am old now and it's time for the young people to take over this position, so I retired. Then I set up the CC CAMPUS NETWORK SDN BHD. It works in with 'the Belt and Road' policy initiated by China which hopes to encourage more students to go to China." In addition, he pointed that:

After all, AGUCCM is a community organization; there is not enough staff, it needs a lot of manpower, material resources and time to engage in education, so I set up this center. Now I have more than 2000 scholarships provided by 20 universities in China including 400 scholarships in Beijing. There are different kinds of scholarships and the best is free of tuition fees and accommodation fees. I go to secondary schools to recommend universities in China. I have almost traveled about $85 \%$ of the independent Chinese secondary schools, $78 \%$ of national-type secondary schools and dozens of national secondary schools. Because there are 890 national secondary schools who have the Chinese subject, so it's impossible to go all of them, it is great if I could finish around one or two hundred, but I must finish all the Chinese independent high schools and national-type secondary schools. I know the independent Chinese secondary schools well because I served there before. Besides, I held Chinese Cultural Competition for Overseas Chinese Youths many times when I was in AGUCCM, which made it easier for me to meet many teachers from national secondary schools and national-type secondary schools.

In sum, the AGUCCM as the collective agent, it has many resources through contacting with China, and all the members are from the graduates of universities from mainland China. Therefore, they can keep a good relationship with Chinese universities and easily get the scholarships from scholarships in China, which are the main resources for the AGUCCM to conduct his action to promote the education exchange between Malaysia and China.

\subsection{The Role of Malaysia-China Friendship Association (MCFA)}

Malaysia-China Friendship Association (MCFA), also known as PPMC (Persatuan Persahabatan Malaysia-China), was formed on 4th December, 1992 by a group of interested personalities, including Mr. Tan Kai Hee, Mr. Lee Lam Thye and many others. The main objective is "to encourage and strengthen the fraternity, understanding and friendship among the peoples of Malaysia and the People's Republic of China". Meantime, it helps the government to enhance bilateral relations between the two countries and to enhance friendship among its members from different ethnic background.

Member of MCFA come from various strata in society including entrepreneurs, investors, scholars, artists, educationists, politicians and professionals, as well as government officials. These human resources could ensure sufficient social resources to MCAF and enable its social practice to promote educational exchange between Malaysia and China.

As a non-governmental organization, PPMC has dedicated itself to the promotion of mutual understanding and friendship between Malaysia and the People's Republic of China at the people to people level. In order to achieve this goal, the association has carried out a variety of social, cultural, educational, youth and sports activities and programs among the peoples between the two countries. Since its establishment, MCFA has carried out many major events and directly participated in many official visits to China, such as Mahathir's visit to China in 1993 and the celebration of the 20th anniversary of the establishment of diplomatic relations between Malaysia and China on May 30, 1994. Besides, MCFA has participated in the official activities of visits by many Chinese leaders to Malaysia. 
Informant A1 who is the president of MCFA gave his reason why he promoted the educational exchange between Malaysia and China, he said that:

Because I think education from this point of view, can increase understanding and increase a better awareness between the two countries, and I think we must tie with the young people, so that's why I propose you know first actually the high level for more Malaysian, Malay students here to go to China.

MCFA promotes educational exchange between Malaysia and China through a variety of ways. Just as informant A1 pointed out that MCFA cooperated with other Chinese NGOs such as Beijing Friendship Association to deal the educational issue. In addition, he said that:

we can start sister school relationship, at the major school between one school in China and one school in Malaysia, so the student that level can do some exchange, they have students program, they have teachers program, so later on we can expand, so I think you know exchange at the educational level, important to aware create awareness especially at the younger level.

In addition, according to the informant A1, MCFA promotes cooperation on education between Malaysia and China through cooperating with Beijing Foreign Studies University (BFSU). In 1996, MCFA convened the Malay Language Studies International Conference in BFSU. This was followed by the establishment of the Malay Language Teaching Centre in 1997 and the Malay Language Study Centre in 2005 (MCFA, 2012). Dato' Sri Najib Tun Razak was the honorary advisor of the Center. In 2007, as a contribution to the Centre's operating fund, Mr. Tan Kai Hee, the General Manager of Hai-O Enterprise Bhd and also the Secretary General of PPMC, made a donation of RM100, 000 to the Malay Language Study Centre of BFSU (MCFA, 2012). In addition, a team of lectures and students from BFSU visited MCFA in Kuala Lumpur on September 3, 2007. The visit was made possible under a special arrangement in collaboration with the Ministry of Education. Interestingly, the meeting was entirely conducted in Bahasa Malaysia. MCFA made great contribution of Malay language exchange between Malaysia and China, which provided many chances for Malaysian students to go further study in China.

Besides, he also mentioned that "we have the ASEAN (Association of Southeast Asian Nations)-China Youth Cultural Exchange Festival every year". Apart from these, in 2009, our association successfully hosted the 4th ASEAN-China People-to-People Friendship Organizations' Conference in Kuala Lumpur. The Conference adopted the Kuala Lumpur Declaration which endorsed new ASEAN-China People-to-People activities, especially among the youth and in the education sector. MCFA has contributed positively to further enhancing of interaction among the peoples of China and ASEAN.

In a word, the main objective of MCFA is to promote better understanding of people among Malaysia and China and enhance good relationships between the two countries. Through it emphasizes on political and economic areas, it also contribute to educational exchange aspect. Through its sufficient human resources, it can easier grasp the social resources to facilitate his action to promote education exchanges. In addition, with the progress of "the Belt and Road", it will play more important role on educational exchange area.

\section{Conclusion}

Though Malaysia is one of the multi-ethnic, multi-culture and multi-religious countries in Southeast Asia, it has a political structure that is based on ethnic politics, As a matter of fact, the ethnic preferential policies affected most domains of this country, including social, political economic and economic areas, especially Chinese education in Malaysia.

The development of Chinese education in Malaysia is undoubtedly a hotly contested area, which was lack of support from the ruling coalition government (Thock \& Tan, 2016). Though Malaysian government stated that Malaysia respected the political reality of pluralistic society and gave Chinese communities a space to develop its own education, the Chinese communities generally believed that it was unthinkable if there was no long-term continuous resistance movement.

Educational exchange between Malaysia and China is significant to Malaysia and China relationship, which has an important interaction with the Chinese education in Malaysia and the political relations between Malaysia and China. Chinese education in Malaysia is twisted with Malaysian ethnic politics. Malaysian Chinese students were lack of opportunities at the public institutions of higher learning due to the preferential and affirmative action policies implemented by Malaysian government for the majority community under the egis of NEP (Raman \& Sua, 2010). Under this circumstance, Malaysia NGOs carried out educational exchange with China to open up a more spacious study channels for students of the independent Chinese secondary schools in Malaysia. 
As noted by the study's data, there are three main important NGOs that play a significant role in promoting educational exchange between Malaysia and China, which are Dong Jiao Zong, AGUCCM and MCFA. The results showed that, as the purposive actors, these three collective agents' action to promote educational exchange between Malaysia and China is earlier than the Malaysian government. In other words, the efforts of the Chinese communities played a pioneer role in promoting educational exchange and opened up the channels for Malaysian students' further studies to China in the early 1990s. Under the structuration which was not favorable to the Chinese education in Malaysia, these communities aimed to solve the problem of further study for Malaysian students especially those in Independent Chinese Secondary Schools at first, but finally they promoted the educational exchange between Malaysia and China and more and more students go to China for further studies.

Based on the structuration theory, Dong Jiao Zong, AGUCCM and MCFA are the purposive agencies who aim to promote educational exchange between Malaysia and China. They conduct their actions based on different levels, which are to develop Chinese education in Malaysia, to continue and inherit Chinese culture. Their unconsciousness reason is based on Malaysian Chinese's deep feeling to China. Their discursive consciousness, practical consciousness and unconsciousness inspired them to promote educational exchange between Malaysia. However, Dong Jiao Zong, AGUCCM and MCFA promoted education exchange under the structure of Malaysian ethnic politics. The rules in the structure constrained their action in the process of promoting educational exchange. The implementations of reports and education ordinances restricted the development of Chinese education in Malaysia. Dong Jiao Zong, AGUCCM and MCFA had to follow the rules through their process of promoting educational exchange. Meanwhile, resources which are under the Malaysian ethnic politics facilitated the action of Dong Jiao Zong, AGUCCM and MCFA. The three purposive agencies have their own material equipment and organizational capacities, which helped them to mobilize power to promote educational exchange.

In addition, the structure of Malaysian ethnic politics led to a dichotomy in educational exchange. The rules in the structure restricted the Chinese education in Malaysia, thus, the Malaysian NGOs had to conduct their practice to develop Chinese education. Meantime, the resources facilitated their actions. In sum, the educational exchange in the aspect of Chinese education is conducted under the structure of Malaysian ethnic politics. The findings of this study show that structuration theory as a ground theory explained the research questions well; in addition, this study proved the rationality of the theory and enriched the theory.

In sum, nowadays, with the rise of China and the promotion of "the Belt and Road", Malaysia-China relations enter the most splendid period in history, Meanwhile, under such background, educational exchange between Malaysia and China will become better and better. It can be expected that educational exchanges and Malaysia-China relations will enter a more perfect and better stage which benefits people of the two countries.

\section{References}

Brant, P. (2015). One Belt, One Road? China's community of common destiny. The Interpreter, 2, 3-31.

Chin, J. (2009). The Malaysian Chinese dilemma: The never ending policy (NEP). Chinese Southern Diaspora Studies, 3, 167-182.

Cohen, I. J. (1989). Structuration theory: Anthony Giddens and the constitution of social life: Macmillan London.

Eng, N. T. (2005). Re-shaping the Party Platforms: The Dong Jiao Zong. Elections and Democracy in Malaysia. Bangi: Penerbit Universiti Kebangsaan Malaysia.

Giddens, A. (1979). Central problems in social theory: Action, structure, and contradiction in social analysis. Berkeley: University of California Press. https://doi.org/10.1007/978-1-349-16161-4

Giddens, A. (1984). The constitution of society: Outline of the theory of structuration. Berkeley: University of California Press.

Heng, P. K. (1988). Chinese politics in Malaysia: A history of the Malaysian Chinese Association. Singapore: Oxford University Press.

Lew, B. H. (2006). The United Chinese School Teachers' Association of Malaysia and Its Leaders (1951-2005). Kajang: The United Chinese School Teachers' Association of Malaysia.

Lim, K. T. (1999). Development of "Chinese Culture": Ethnic Belonging, National and Chinese Education Movement. Kuala Lumpur: Huazi Resource and Research Centre.

MCFA. (2012). Celebrating 20th Anniversary (1992-2012): A Journey of Friendship Persatuan Persahabatan 
Malaysia-China (PPMC).

Raman, S. R., \& Sua, T. Y. (2010). Ethnic segregation in Malaysia's education system: enrolment choices, preferential policies and desegregation. Paedagogica Historica, 46(1-2), 117-131. https://doi.org/10.1080/00309230903528496

Ritzer, G. (2010). Sociological theory (8th ed.). New York: McGraw-Hill Education.

Shi, C. J., \& Pan, L. (2011). A Brief Analysis on the Association of Graduates from Universities and Colleges of China in Malaysia. Southeast Asian Studies. 3, 12-19.

Thock, K. P. (2016). The Impacts of Globalization and Rise of China on Overseas' Chinese Education: Case Study of the Development and Sustainability of Independent Chinese Secondary Schools in Malaysia. Paper presented at the 9th International Conference of ISSCO, 6-8 July 2016, University of British Columbia, and Vancouver, Canada.

Thock, K. P., \& Tan, Y. S. (2016). Identity and Cultural Contestation in a Plural Society: The Development of Chinese Education in Malaysia. Journal of Chinese Literature And Culture, 2(1), 156-175.

Turner, J. H. (1986). Review Essay: The Theory of Structuration. American Journal of Sociology, 91(4), 969-977. https://doi.org/10.1086/228358

Xu, W. R. (2004). The study of Political Resistance Poetics of Malaysian Literature in Chinese. Johor Bahru: Southern College.

Zou, S. H. (2014). DongZong 60th Anniversary 1954-2014. Kajang: United Chinese School Committees Association of Malaysia.

\section{Copyrights}

Copyright for this article is retained by the author(s), with first publication rights granted to the journal.

This is an open-access article distributed under the terms and conditions of the Creative Commons Attribution license (http://creativecommons.org/licenses/by/4.0/). 